\title{
KETAMINE INCREASES THE FUNCTION OF $\gamma$-AMINOBUTYRIC ACID TYPE A RECEPTORS IN HIPPOCAMPAL AND CORTICAL NEURONS
}

\author{
Dian-Shi Wang ${ }^{1}$, Antonello Penna ${ }^{2}$, Beverley A. Orser ${ }^{3}$ \\ Department of Physiology, University of Toronto. \\ Department of Physiology, University of Toronto; Department of Anaesthesia, Universidad de Chile. \\ Departments of Physiology and Anesthesia, University of Toronto; Department of Anesthesia, Sunnybrook.
}

Introducción: The "dissociative" general anesthetic ketamine is a well-known NMDA receptor antagonist ${ }^{1}$. However, whether ketamine, at clinically relevant concentrations, increases the activity of inhibitory $\mathrm{GABA}_{\mathrm{A}}$ receptors in different brain regions remains controversial ${ }^{2,3,4}$. Here, we studied the effects of ketamine on synaptic and extrasynaptic $\mathrm{GABA}_{\mathrm{A}}$ receptors in hippocampal neurons. Ketamine modulation of extrasynaptic $\mathrm{GABA}_{\mathrm{A}}$ receptors in cortical neurons was also examined.

Objetivo General: To determine whether ketamine potentiates the function of extrasynaptic and synaptic $\mathrm{GABA}_{\mathrm{A}}$ receptors in the hippocampus and cortex.

Material y Métodos: Whole-cell currents were recorded from primary cultures of hippocampal and cortical neurons of mice. Current evoked by exogenous GABA, miniature inhibitory postsynaptic currents, and currents directly activated by ketamine were studied. Data are represented as mean \pm S.E.M. together with the $95 \%$ confidence interval of the mean (CI). Student's t test (paired or unpaired), one-way analysis of variance (ANOVA), two-way ANOVA were used where appropriate. Cumulative distributions of the amplitude and frequency of mIPSCs were compared using the Kolmogorov-Smirnov test. Pearson correlation coefficient was used to measure the strength of concentration-dependent effects. Statistical significance was set at $p<0.05$. No statistical power calculation was conducted prior to the study. The sample size was based on our previous experience with this experimental design.
Resultados: Ketamine did not alter the amplitude, frequency or kinetics of synaptic currents but increased a tonic inhibitory current generated by extrasynaptic $\mathrm{GABA}_{\mathrm{A}}$ receptors in hippocampal neurons. For example, ketamine $(100 \mu \mathrm{M})$ increased the tonic current by $33.6 \% \pm 6.5 \%$ (mean \pm S.E.M.; $95 \%$ CI, 18.2 to $48.9 ; \mathrm{n}=8, \mathrm{p}<0.001)$. Ketamine shifted the GABA concentration-response curve to the left, but only when GABA receptors were activated by low concentrationsof GABA $(n=6)$. The selective increase in tonic current was attributed to ketamine increasing the apparent potency of GABA at high-affinity extrasynaptic GABA receptors. Ketamine also potentiated a tonic current in cortical neurons $(\mathrm{n}=$ 11). Ketamine directly gated the opening of GA$\mathrm{BA}_{\mathrm{A}}$ receptors, but only at high concentrations that are unlikely to occur during clinical use.

Conclusiones: The results show that ketamine preferentially increases a tonic inhibitory current generated by extrasynaptic $\mathrm{GABA}_{\mathrm{A}}$ receptors but has no effect on synaptic $G_{A B A}$ receptors in hippocampal and cortical neurons. The increase in tonic current but not synaptic currents is attributed to the selective increase in potency of GABA at high-affinity extrasynaptic GABA $_{A}$ receptors. The ketamine-induced increase in tonic current likely contributes to the drug's desired anesthetic properties.

\section{References}

1. Anesthesiology 1997;86:903-17.

2. Anesthesiology 2000;92:1418-25.

3. Br J Pharmacol 1985;85:675-81.

4. J Neurosci 2008;28:5383-93. 